\title{
Aortic Valve Insufficiency
}

National Cancer Institute

\section{Source}

National Cancer Institute. Aortic Valve Insufficiency. NCI Thesaurus. Code C51223.

Dysfunction of the aortic valve characterized by incomplete valve closure. 